\title{
EVALUATING PARTICIPATORY MODELING: DEVELOPING A FRAMEWORK FOR CROSS-CASE ANALYSIS
}

Natalie A. Jones, Pascal Perez,

Thomas G. Measham, Gail J. Kelly,

Patrick D'Aquino, Katherine Daniell, Anne Dray and Nils Ferrand 
Further information: Clive Spash - www.clivespash.org

Bev Rose - bev.rose@csiro.au

CSIRO Sustainable Ecosystems

GPO Box 284, Canberra ACT 2601

Australia

www.csiro.au

(c) CSIRO 2007. All rights reserved.

This work is copyright. Apart from any use as permitted under the Copyright Act 1968 (Cwlth), no part may be reproduced by any process without prior written permission from the Commonwealth. 


\title{
Evaluating Participatory Modeling: Developing a Framework for Cross- case Analysis
}

Natalie A. Jones ${ }^{1}$, Pascal Perez ${ }^{2}$, Thomas G. Measham ${ }^{3}$, Gail J. Kelly ${ }^{4}$, Patrick D'Aquino ${ }^{5}$, Katherine Daniell ${ }^{6}$, Anne Dray $^{7}$ and Nils Ferrand ${ }^{8}$

\begin{abstract}
Participatory modeling is increasingly recognised as an effective way to assist collective decision-making processes in the domain of natural resource management. This paper introduces a framework for evaluating projects that have adopted a participatory modeling approach. This framework - known as the 'Protocol of Canberra' - was developed through a collaboration between French and Australian researchers engaged in participatory modeling and evaluation research. The framework seeks to assess the extent to which different participatory modeling practices reinforce or divert from the theoretical assumptions they are built upon. The paper discusses the application of the framework in three case-studies, two from Australia and one from the Pacific island of the Republic of Kiribati. The paper concludes with some comments for future use of the framework in a range of participatory modeling contexts, including fostering consideration of why and how different methodological approaches are used to achieve project aims and to build a collective vision amongst diverse stakeholders.
\end{abstract}

Keywords: participation, modeling, evaluation, complex systems science

\footnotetext{
1 School of Natural and Rural Systems Management, University of Queensland, Brisbane, Australia n.jones3@uq.edu.au

2 Australian National University / CIRAD, Canberra ACT 0200, Australia

3 CSIRO Sustainable Ecosystems, GPO Box 284, Canberra ACT 2601, Australia

4 Bureau of Rural Sciences, GPO Box 858, Canberra ACT 2601, Australia

5 CIRAD, UPR-GREEN, Montpellier 34398, France

6 CEMAGREF, UMR-GEAU, Montpellier 34396, France / Australian National University, Canberra ACT 0200, Australia

7 Research School of Pacific and Asian Studies, Australian National University, Canberra ACT 0200, Australia

8 CEMAGREF, UMR-GEAU, Montpellier 34396, France
} 


\section{INTRODUCTION}

Participatory modeling, an approach combining participatory procedures with modeling techniques, is increasingly recognised as an effective way to assist collective decision-making processes dealing with natural resource management (Barreteau et al., 2007). The rationale underlying this approach asserts that by gathering and integrating a diversity of viewpoints belonging to local, expert and/or specialised stakeholders, a collective vision for managing a common resource can be established and effectively worked towards. This rationale has been interpreted from a range of disciplinary standpoints (including social, environmental and computer science) and translated into a variety of techniques and procedures (Lynam et al., 2007). Minimal attention, however, has been directed towards understanding how such techniques play out in practice (Siebenhuner and Barth, 2005). This paper will discuss the process of developing a framework for evaluating projects that have adopted a participatory modeling approach. This framework known as the Protocol of Canberra - seeks to assess the extent to which different participatory modeling practices reinforce or divert from the theoretical assumptions they are built upon. The paper will conclude with a brief discussion on the methodological process of using the Protocol of Canberra to evaluate three diverse case-studies.

\section{PARTICIPATORY MODELING AND THE NEED FOR EVALUATION}

In order to deal with complex issues, natural resource management initiatives are increasingly turning towards participatory modeling procedures to effectively integrate local and scientific sources of knowledge. The practice of modeling has long been acknowledged as an effective, and in many cases necessary, way to represent reality and to explore a diversity of problems at a variety of scales. At an 
individual scale, model building is considered an essential prerequisite for human comprehension via an individual's 'mental model' (Costanza and Ruth, 1998). At a systems level, advances in information technology have led to an increased reliance on computer models to assist decision-making in complex systems (Siebenhuber and Barth, 2005). Models can help their users to understand characteristics of complex management systems, such as the role of social networks, trust and sense of place in regional decision making (McAllister et al., 2006; Alexandridis and Measham 2007). While a model may exist in a great number of forms it is important to recognise that model building is essentially a subjective process. The legitimacy of the decision-making process relies partly on the acceptance of the model used to help solve the decision problem. Questions concerning 'Whose reality is represented in the model?' and 'Whose hypotheses and assumptions is it built upon?' are central to the model development process.

While harnessing the benefits of modeling (Table 1 ), the practice of participatory modeling deals with the subjective character of a model by making the process of developing and providing an abstraction of reality a 'collective process'. The approach seeks to integrate different points of view and representations of reality through collectively building a common model. This means involving a range of stakeholders with differing, and often contrasting, worldviews. This is aligned with sustainability science which calls for reflexive scientific practices. Participatory modeling promotes the co-generation of solutions amongst different types of stakeholders and takes account of uncertainty and different knowledge bases including local knowledge, expert or specialised knowledge and strategic knowledge (Blackstock et al., 2007; Brown and Pitcher 2005). 
Participatory processes that involve a diversity of participants who represent multiple stakes is considered a key dimension of post-normal science, a form of science which attempts to address complex problems where expert knowledge alone is inadequate (Funtowicz and Ravetz, 1991). Participatory procedures are used to actively involve stakeholders in decision-making processes for three reasons: normative, substantive and instrumental (summarised in Table 2). Depending on the objectives of a project, the weighted value placed on each of these rationales will differ, influencing the selection of participatory procedures and the modeling techniques used. The notion of participation, like 'modeling', is conceptually broad and can mean different things to different people. At one level it may involve the transfer of knowledge from one group (or individual) to another, while at another level, participants may engage in the co-production of knowledge.

\section{TABLE 2 ABOUT HERE}

The somewhat broad theoretical underpinnings of participation and modeling converge into the participatory modeling approach. This approach may be adopted to achieve a wide range of objectives. Daniell and Ferrand (2006) identify the following:

- gaining a common understanding of a problem or issue;

- $\quad$ assisting collective decision making processes;

- $\quad$ explicating tacit knowledge, preferences and values;

- $\quad$ improving the legitimacy of a model;

- $\quad$ reducing conflict;

- $\quad$ enhancing both individual and social learning; 
- $\quad$ promoting creativity and innovation;

- $\quad$ investigating individual behaviors and collective dynamics in a controlled environment; and

- informing and enhancing collective action.

As the literature on the theoretical rationale behind participatory modeling continues to grow, including discussions on the development of associated methodologies and procedures, minimal attention is paid to evaluating how such an approach actually plays out in practice. To what extent and under what circumstances does participatory modeling aid decision-making processes, or other intended objectives, when implemented? Broadly speaking, an evaluation seeks to assess a project, or series of projects to understand what works for whom, and in what situation. In response to the lack of experiential reporting concerning participatory modeling, a wide-scale evaluation study, funded by the Agence Nationale de Recherche (France), has been set up to evaluate 30 case studies across the world (ANR, 2005). The project, in which the present research is embedded, aims to (i) create a robust evaluation framework, (ii) use this framework to evaluate individual projects, and finally (iii) compare project implementations and outcomes with common metrics.

The majority of these cases are based on the 'Companion Modeling' (ComMod) approach, a specific form of participatory modeling that uses role-playing games and agent-based models to assist collective learning and decision-making processes (Bousquet et al, 2002). A detailed theoretical rationale underlies the ComMod approach in a formalised charter (ComMod, 2004). Other cases evaluated adopt a more general view of participatory modeling; in one case the model takes 
the form of a 'Futures Simulator' (Goddard, 2005) while in another it is a 'Risk Analysis' tool (Daniell, 2007). While variation exists in the form and complexity of the model used as well as the level of participation required, the proposed common evaluation framework aims to better understand:

- $\quad$ The capacity of participatory modeling to achieve a collective decision;

- The capacity of participatory modeling to better integrate local actors in a collective decision process;

- The influence of the researchers upon the outcomes of the participatory process;

- The level of integration of the approach into the existing social and institutional networks; and

- The capacity of local actors to engage with the design and implementation of the approach.

The remainder of this paper will discuss the process of developing a framework for evaluating participatory modeling approaches in practice using crosscase analysis. It will conclude with a brief discussion on the evaluation process applied to three projects using the framework developed.

\section{DEVELOPING THE EVALUATION FRAMEWORK}

Literature that looks specifically at participatory modeling evaluation is limited, with the most pertinent insights coming from the field of Integrated Assessment (IA). IA is the interdisciplinary process of synthesising, interpreting and communicating knowledge from diverse disciplines with the aim of providing policy-makers with relevant information to make decisions (Hisschemoller et al., 2001). Computer 
modeling plays an important role in achieving IA aims by simulating and examining complex and dynamic systems, while participatory procedures are increasingly used to enhance the usability and usefulness of the results produced. Research has been carried out within the discipline to examine under what circumstances the strengths of model use align, or come in to conflict, with the purposes of participatory procedures (Hisschemoller et al., 2001; Siebenhuner et al., 2005). Here, the theoretical underpinnings of both model use and participatory procedures are used to structure the assessment. These authors' research also focuses on identifying 'where' (at what stage in a project) and 'how' modeling and participation can deliver a meaningful contribution. In the interest of developing an evaluation framework, Hisschemoller et al., (2001) and Siebenhuner et al., (2005) highlight the value of looking closely at the methodologies and procedures adopted in a project's design and assessing the extent to which they prove successful in fulfilling anticipated functions or reaching intended outcomes. This involves gaining an insight into the tools and methods used in a project (what was implemented and how) and the rationale behind their application. The IA literature serves as a useful guide for developing an evaluation framework that aims to assess the extent to which different participatory modeling practices, when implemented in a certain context, reinforce or divert from the theoretical assumptions they are built upon.

This approach to evaluation is aligned with Webler (1999) who proposes a 'craft-theory dialectic' as a way to advance the field of public participation. This comes as a response to the realisation that "the field is characterised by a rich base of experiential knowledge and scattered, but growing literature on theory" (Webler 1999: 55). He suggests that there is a need to enable practice to learn from theory, and theory to learn from practice. Participatory modeling is likewise characterised by 
a wealth of practice and it is often carried out in an iterative manner, meaning successive approximations are required to arrive at a more widely accepted solution. A great deal of practice stems from individual reflections with the common sense of local contingencies an important force in driving each project forward. An effective evaluation framework should capture this reflexive dimension interacting with the underlying theory in order to understand the structural logic of a project. Creighton (cited in Webler, 1999) points out that to advance the field of public participation, it is important to go beyond focusing on 'what works' and strive to answer 'why it works' and 'how it could work better'. Integrating these latter questions into an evaluation framework would assist in tying theory with experiential knowledge, further supporting and building on existing understandings of participatory modeling (Webler 1999).

\section{DESIGNING THE EVALUATION FRAMEWORK}

\section{Objective}

To carry out a cross-case analysis of heterogeneous projects, an initial step in the framework development process involves defining an object of comparison, or unit of analysis. Cash et al. (2003) and Reed et al. (2005) draw attention to the problems associated with setting conceptual boundaries in sustainability science projects due to the complexity of socio-ecological systems. The boundaries of these projects are often flexible in terms of scope and duration, making it difficult to know where a project starts and ends. This highlights the importance of identifying the unit of analysis so evaluators know precisely what they are evaluating. The importance of this task is further accentuated when considering the many elements of diversity characterising multiple participatory modeling projects, including the:

- $\quad$ variety of participatory modeling techniques used; 
- different issues or problems addressed (often related to natural resource management);

- $\quad$ interdisciplinary nature of project implementation;

- involvement of project evaluators with diverse scientific and cultural backgrounds; and

- focus on both continuing and completed projects: some case-studies are subject to an 'on-going' form of evaluation, where as already completed projects undergo an 'ex-post' evaluation.

To clearly identify the object of comparison the question must be posed: what commonalities are shared between all participatory modeling projects? In considering potential applications for this framework, it was noted that all share a set of 'theoretical assumptions' which underlie their procedural logic. These assumptions are strongly tied to notions of 'participation', 'utilisation of mediating tools', '(collective) learning' and 'collective decision-making in complex situations'. Understanding how these assumptions are interpreted in different projects spanning a range of ecological, institutional, political and social contexts - is central to assessing how different aspects of a participatory modeling project may be implemented and what the outcomes are. It is a project's design and supporting rationale, made up of a sequence of tools and procedures, implemented in a specific context, that together form the object of comparison or unit of analysis. The framework developed, called the Protocol of Canberra, is thus structured around identifying a project's context (including objectives to be achieved), process (the methods and tools used) and underlying theoretical thread tying it all together. The latter allows for an unpacking of assumed relationships constituting the participatory 
modeling approach. This approach to evaluation is supported by the 'theory-based evaluation' paradigm which is specifically geared towards capturing a project's logic. It allows for an in-depth understanding of the workings of a project and serves to prioritise issues to investigate in greater depth (World Bank 2004). The premise is that underlying the vast majority of projects is a theory - either explicit or implicit about how and why the project should work (Curnan et al., 1998).

Theory-based evaluation essentially involves developing a project logic model - or picture - describing how the project works. Argyris (cited in Patton, 1990) refers to this as a project's 'espoused theory', what a project team claim should happen in a project, while the 'theory-in use' is what really happens. The Protocol of Canberra seeks to capture the espoused theory by working with a project team to identify the sequence of methods used and their anticipated effects (Figure 1). The theory in use is assessed from the point of view of both the project team and the participants on what actually happened in practice. Following Curnan et al. (1998), it is assumed that by identifying specific methods (and their corresponding tools) associated with explicit effects a great deal can be learned about the project's impact and most influential factors. An important aim of our evaluation task is to identify and explore those 'influential factors' to advance the field of participatory modeling.

\section{FIGURE 1 ABOUT HERE}

The Protocol of Canberra (PoC) Evaluation Framework

The Protocol of Canberra Evaluation Framework (Figure 2) consists of two main components: the Designers Questionnaire (DQ) and the Participants Evaluation Guide (PEG). While the former is used to capture the project team's experiences, including the theoretical logic underlying the design of the project, the latter guides the task of gaining an understanding of the participants' experiences of the project. 
In Argyris' (cited in Patton 1990) terms, the espoused theory is identified through the project's theoretical logic. The theory in use is comprised of both the project team's experiences and the participants. Table 3 provides a summary of the data collection methods that can be used to inform the Protocol of Canberra.

\section{TABLE 3 ABOUT HERE}

\section{Designers Questionnaire}

The DQ specifies what information is to be collected from the project team. It is filled in by the evaluator using information gathered through an interview with the project team and gleaned from existing project documents and reports. Project documents provide a rich source of background information to a project giving the evaluator a good overview of the project. For on-going evaluations, the evaluator's observations can also be used as a source of data. The $D Q$ is broken down into two subcomponents: the 'Context' and the 'Process'.

The Context: Every project takes place in a social, political and ecological context which influences its design, how it functions and the outcomes. When evaluating for the purpose of understanding what works and why, it is important to know in what context. When dealing with natural resource management issues, the socio-political setting and physical setting lie at the heart of the collective decision-making process. The ComMod approach is geared towards exploring the interactions between social and ecological dynamics. The Context section of the DQ looks at the suitability of different participatory modeling procedures when applied within certain socio-political and physical settings. The project objectives are also relevant as it is important for the evaluator to know the intention of the project. The evaluation will determine the influence of the methods and tools adopted in achieving the intended objectives. Here, the DQ is also interested in the project team's rationale for using a 
participatory modeling approach. This will assist in building on the current theoretical assumptions underlying the ComMod approach and participatory modeling approach in general. The evaluator can use this rationale to tease out and extract criteria to listen out for and follow-up on during interviews with the participants to effectively unpack the relationships between theory and practice.

The Process: This component of the DQ systematically captures the design of the project and the sequence of methods used. The project team and evaluator work together to structure the project process into a series of implemented methods (or steps); however, knowing and deciding where these start and end can be a challenging task in some projects. It is through this sequence of methods that the project logic is traced. The idea behind the method section of the DQ is to identify the critical blocks in a project that have a strong bearing on the process and overall outcomes. Once these blocks are identified it is possible to examine their inner workings according to a set of overarching evaluation research questions. These critical blocks also serve to systematically focus the participant interviews using the PEG (discussed below). Gaps between implemented tasks, theoretical assumptions and outcomes achieved (as perceived by both the project team and participants) can be identified and explored.

The utilisation of mediating tools (or models) is central to the participatory modeling approach. This aspect of the Protocol of Canberra is based on a similar participatory modeling evaluation initiative known as HarmoniCOP - Harmonising Collaborative Planning (Mostert et al., 2007). A major part of this work involved the development of a framework to assess the role of information and communication tools (IC-tools) in participatory processes. Elements of the HarmoniCOP framework have been adopted in the Protocol of Canberra. For each method using a tool or 
model, the project team state why it was used and comment on a set of criteria derived from the HarmoniCOP literature (Maurel et al., 2004). These criteria are grouped into three themes which look at the tools influence on: (i) the sharing of information amongst participants; (ii) relations amongst participants; and (iii) the outcomes of the participatory process.

Participants Evaluation Guide (PEG)

The PEG assists the evaluator in determining what information to collect from participants to gain an understanding of their experiences of the participatory modeling process. The PEG mirrors the DQ so that the participants' responses can be compared and contrasted with those of the project team. This provides a well rounded picture of how a participatory modeling initiative plays out in practice according to all involved. In recognising that the project context will have a strong bearing on how the participant interview questions should be phrased, the PEG acts a guide only. The evaluator works with the project team to tailor the questions to the local context and determine how this information can be collected. In mirroring the DQ, the PEG is interested in gaining an understanding of the participants' idea of the context around which the project was designed: what the objectives of the project were; who participated and why. In terms of methods, the critical block(s) of the project (identified through the DQ) form the basis of the interview questions posed to participants. Here, the interest is in knowing what a participant liked or disliked about participating in the method (such as a role-playing game) and what they got out of it. 


\section{APPLYING THE EVALUATION FRAMEWORK}

The aim of this paper is not to provide accounts of individual project evaluations, but rather to demonstrate how the Protocol of Canberra might be used in different contexts. Thus, we have selected three contrasted case studies from the ADDComMod project (ANR, 2005). These case studies differ by their topics, the participatory methods implemented, and the stage at which the evaluation takes place (on-going or ex-post), as indicated in Table 4. An on-going evaluation is carried out during the project as it progresses whereas an ex-post evaluation is conducted after the process has been implemented.

\section{TABLE 4 ABOUT HERE}

AtollGame represents the majority of case studies included in the ADDComMod project as it (i) refers explicitly to the companion modeling approach and (ii) uses the traditional tools of this approach (Bousquet et al., 2002). The Hawkesbury and Catalyst case studies belong to the broader 'participatory modeling' community. Furthermore, the Hawkesbury case study offered the opportunity to perform an ongoing evaluation alongside the project's implementation. Thus, it seems relevant to test the robustness of our Protocol of Canberra against these contrasted case studies. For each case study, the evaluation proposed by the ADD-ComMod project has two key objectives: (i) to evaluate its capacity to enhance the quality of collective decisions, and (ii) to identify specific and replicable methods having effective outcomes. For each method implemented, three types of outcomes are targeted which, for the evaluation task at hand, are considered inherent to the espoused theory of the participatory modeling approach:

- $\quad$ Creating and maintaining a space for exchange of knowledge and viewpoints: 
- $\quad$ Did participants feel comfortable interacting and exchanging viewpoints with others?

- $\quad$ Did this space continue to evolve within or beyond the project?

- $\quad$ Shared knowledge:

- Did the method support participants in building on their collective knowledge together?

- $\quad$ Did the method integrate different forms of knowledge?

- $\quad$ Promoting collective practices:

- $\quad$ Did collective practices emerge from the implemented method?

- $\quad$ Did these collective practices follow through to implementation?

For each case study, the evaluation includes the co-construction between the evaluator and the designer(s) of a sequence diagram including all the methods and tools used during the participatory process (see Figure 1). Each of these methods is then explored within the Designer's Questionnaire. From here, significant (or critical) methods are selected as the focus of the participant interviews. The following casestudies provide a brief snapshot of the evaluation data collected using the DQ and PEG, indicating points of alignment and discrepancy between these datasets according to the targeted outcomes outlined above.

\section{AtollGame}

Context

The AtollGame project (Dray et. al., 2006) addresses the highly contested issue of groundwater management in the Republic of Kiribati, a small atoll nation situated in the Pacific. The project was designed to provide local actors with relevant 
information to facilitate dialogue and promote collective exploration of sustainable and equitable water management practices. AtollGame is based on the Companion Modeling approach and uses a computer-assisted Role-Playing Game (RPG) as a mediating tool to facilitate discussions. The RPG was implemented via a two-day workshop three years prior to the evaluation being carried out. In order to build the RPG, a series of interviews were conducted with stakeholders to gather different viewpoints on the social and biophysical dynamics of the groundwater system. These collected viewpoints (belonging to community, government and scientific stakeholders) were integrated into the computer-assisted RPG (Dray et al., 2007).

\section{Evaluation Process}

First, the evaluator consulted relevant project documentation before interviewing two of the project designers using the Designer's Questionnaire. This interview took approximately 5 hours to complete and succeeded in gaining a description of each step implemented in the project process. Responses concerning the lessons learnt - what went right and wrong - provided the richest insights into the project process. The project team and evaluator decided that the Role Playing Game (RPG) should be the focus of the participant evaluations, as this was the only method clearly addressing the three outcomes listed above (i.e. 'space of exchange', 'shared knowledge', and 'promoting collective practices'). A set of semi-structured interview questions were written up based on the PEG. A project team associate based in Kiribati was re-hired to organise the participant interviews. Thirteen of the sixteen RPG participants took part in the evaluation. Landowners were interviewed at their homes in I-Kiribati language whereas government representatives were interviewed at their place of work in English. All interviewees appeared relatively comfortable 
with the questions despite the fact that the RPG had been held 3 years prior to the evaluation. Table 5 provides an overview of the evaluation.

\section{TABLE 5 ABOUT HERE}

Evaluation of the RPG method

The 2-day RPG workshop involved 16 participants made up of community members, government representatives and one representative from the overarching SAPHE (Sanitation, Public Health and Environment) project. The project team relied on the assumption (espoused theory) that "you can implement collective action in reality only through collective thinking and collective agreement. The RPG and participatory modeling process is helping this collective thinking and supporting the collective implementation, that is sustainable collective action.......We wanted to ensure the game supported good communication, confidence and trust between all the parties. That was the first objective of this computer-assisted game session". The RPG was thus designed to initiate and promote dialogue between the participants in a nonconfrontational manner. The ethnographic techniques used during the targeted global appraisal (Dray et al, 2006) were instrumental in informing the design process. Only common viewpoints and shared representations were used in order to secure a neutral status to the computer-assisted RPG. A brief summary of the evaluation data is presented in Table 6.

\section{TABLE 6 ABOUT HERE}

The Catalyst Project

Context

The Catalyst Project (see Gorddard, 2005), carried out by the CSIRO, was designed to help communities and governments within a region develop their capacity for 
evidence-based strategic planning using a systems thinking approach. The project is aimed at assisting regions to think about the future in a systemic way and is structured around the 'Regional Development Futures (RDF) Framework Loop' (Kelly and Walker, 2004). The RDF consists of four phases:

1. Developing Partnerships: building relationships with community, government and industry and developing an understanding of the key issues within the region.

2. Creating the Foundation: understanding past and current resources and trends. Collecting qualitative data to identify values that may be driving changes.

3. Opportunities for Change: using participatory techniques to gain a systems understanding of the region.

4. Building Resilient Futures: develop evidence-based decision-making tools to explore future development options.

The participants in the Catalyst project included planning staff from federal, state and local government organisations as well as industry and, to a lesser extent, community representatives. The project team moved through one cycle of the RDF with the regional stakeholders with the intention of building the capacity of the region so they could carry on the cycle in the future.

\section{Evaluation Process}

The ex-post evaluation began by reviewing the relevant project documents, consisting of progress reports written up at various stages throughout the process. Internal evaluations also provided a useful source of information. The RDF is made up of a series of well defined steps providing a logical means to begin breaking up 
the project to fit into the DQ, as seen in Table 7. A closer examination of these steps led to a few of them being consolidated.

\section{TABLE 7 ABOUT HERE}

Many of the steps making up the process were dense in terms of what was involved and what had been achieved, making it difficult to adequately capture them all in the DQ. The project documents provided a valuable source of information to make up this shortfall in understanding. In retrospect, it would have been beneficial to brush over some of the steps in the interview and focus more intently on others. Although it is easy to identify the less relevant steps as the evaluation progresses, they all contribute in some way to the evaluator's understanding of the project process. For the participant evaluation, the Catalyst project team worked with the evaluator to decide which steps would be most appropriate to structure the participant interviews around. The most significant aspect of the project, from a participatory modeling perspective, was the process of building the Futures Simulator, beginning with the systems diagram workshops. As in the AtollGame case, the participant interviews were semi-structured, consisting of open-ended questions based on the PEG. A total of 8 participants were interviewed, with an average interview time of 1 hour.

\section{Evaluation of the Futures Simulator Modeling Process}

A core component of the Catalyst project was building the Futures Simulator. This involved three main participatory modeling stages. The first consisted of systems thinking workshops (36 in total). The objectives were to identify the key drivers of change, explore the interconnections between economic, social and environmental issues, and investigate the possible flow on consequences of decisions made. Participants used systems tools to assist them in talking with each other about the 
different parts of the regional planning system and how they fit together. The next stage involved a series of scenario workshops aimed at identifying a set of plausible strategies that could be used as the foundation for building the Futures Simulator. The third stage was the actual modeling of the Futures Simulator achieved through both on-on-one modeling and group modeling activities. Together, these three stages were designed to:

- $\quad$ Explore how links among sectors drive long term behavior of the region.

- $\quad$ Assess how the region may behave in response to future trends and policy options.

- $\quad$ Flag issues that might arise given different development pathways and guide further investigations.

A summary of the Catalyst evaluation results are provided in Table 8.

\section{TABLE 8 ABOUT HERE}

Lower Hawkesbury Estuary Management Plan

Context

The Lower Hawkesbury Estuary Management Plan (LHEMP) Project (see Daniell, 2007), carried out in New South Wales (Australia), differed to the previous two cases discussed in that it underwent an 'on-going' form of evaluation. The aim of the project was to engage relevant stakeholders in the collective decision making process for creating a management plan for the Lower Hawkesbury Estuary. It sought to reduce parochial attitudes towards estuary management by implementing a coordinated, "whole-of-estuary" approach which operates according to catchment boundaries rather then local government boundaries. This meant integrating a range 
of different stakeholder perspectives - communities', government representatives', industries' and scientists' - to establish future visions for the sustainable development of the estuary. A participatory modeling approach was adopted to achieve the project objectives through a series of three workshops as outlined in Table 9. For the purpose of demonstrating the applicability of the Protocol of Canberra, the following evaluation will focus on Workshop 2 only.

\section{TABLE 9 ABOUT HERE}

\section{Evaluation Process}

The context component of the DQ was filled in by the project team during a project planning meeting (without the presence of the evaluator). Questions relating to the 'espoused theory' (what should happen) came from the project team, whereas questions concerning the 'theory in use' (what actually happened) came from the evaluator through observations, informal interactions with participants and debriefing sessions with the project team. Data informing the DQ in the section below thus includes the perspectives of the project team and the evaluator. Observations and interactions with the participants provided rich sources of evaluation data lacking from the previous two ex-post cases discussed. This data was taken on board by the project team and fed back into the process to improve the overall project. The 'theory in use' data collected by the evaluator was complemented with data collected from participants by way of a questionnaire at the end of each of the three workshops. Due to logistics, it was not possible to carry out lengthy interviews with participants. The questionnaire consisted of both open and closed-format questions. It took about 15 minutes to complete with an average return rate of $60 \%$. The questionnaire data was not as rich as that collected through semi-structured 
interviews, however, it succeeded in gaining a succinct picture of the participants' experiences.

Evaluation of Workshop 2 - Risk Analysis

The one day workshop was attended by 19 participants from various government departments, authorities and industries. This workshop only involved stakeholders with governance roles in the estuary or those with commercial interests, referred to here as 'agency' representatives. The aim was to perform a 'risk assessment' on a number of issues associated with estuary management as identified in Workshop 1. A brief summary of the evaluation data is presented below.

\section{TABLE 10 ABOUT HERE}

\section{DISCUSSION}

The above cases demonstrate the Protocol of Canberra's applicability to a set of - in many ways - contrasted participatory modeling projects. The evaluation framework was useful for providing insight into the different factors influencing the engagement of stakeholders in collective decision-making processes using participatory modeling techniques. A brief snapshot of the collected evaluation data presented above highlights some of these aspects, such as the relative importance of language which was seen differently by community participants and the project team, as in the case of the AtollGame. It also shows differences in the expectations for the model developed from the research process, as was the case in the Catalyst study. Furthermore it demonstrated the difficulties and advantages which can arise when stakeholders are excluded from some of the processes, as evidenced in the Hawkesbury study. 
A comparison of the three case-studies show they all were successful at creating a non-threatening 'space of exchange' where stakeholders with differing points of view could effectively interact. In terms of 'shared knowledge' the cases show mixed levels of success, with the factor of time proving problematic in the two cases involving a limited number of participatory workshops, i.e. the AtollGame (one workshop) and the Hawkesbury study (2 workshops at the time of the evaluation). The Catalyst case in using systems thinking techniques was the most successful in this area and interestingly involved over 50 workshops over the life of the project. At the time of conducting the evaluation, all three projects had achieved little in terms of 'promoting collective practices'. In the Hawkesbury case, however, the projects' design lays out clear steps for the identification of collective practices in the future stages of the project.

When looking at the data collected using the Designers Questionnaire compared with that of the Participatory Evaluation Guide from a 'methodological' point of view some important points emerge which warrant consideration when considering the framework for future evaluation initiatives. Out of all three cases, the Hawkesbury case shows the least discrepancy in the perspectives captured in the Designers Questionnaire (informed by the project team and evaluator) compared with the perspectives of the participants. This evaluation was conducted in an ongoing capacity. 'Theory in use' data was collected throughout the process by way of informal discussions with participants, observation and questionnaires filled in immediately after the participants' engagement with the project. As the activities were fresh in the minds of all involved, responses were more focused and the strengths and weaknesses of the participatory modeling techniques were better articulated than in the ex-post evaluations. Process outcomes revealed through the 
evaluation, particularly those unanticipated by the project team, were taken into account in the design of the subsequent stages of the project.

The greatest discrepancy in data, on the other hand, was evident in the AtollGame case drawing attention to three methodological factors worthy of consideration: (1) the length of time between project implementation and evaluation; (2) the use of an interpreter; and (3) cultural differences. Almost three years had passed since the project was implemented affecting the quality of data collected from the project team, and more importantly, the participants. Some participants had problems remembering details of the RPG workshop and at times confused other water management education initiatives with what had taken place in AtollGame. Using an interpreter to conduct the interviews also influenced the quality of data. Kluckhohn (cited in Phillips, 1960) identifies three problems associated with using interpreters: (1) the interpreter's effect on the interviewee; (2) the interpreter's effect on the communicative process; and (3) the interpreter's effect on the translation. The cultural setting in which the interview is conducted raises another issue. In the AtollGame case, few negative comments about the project were received from participants.

While the AtollGame case directly engaged participants in a collective decision-making process, the Catalyst Project was concerned with developing the capacity of the regional stakeholders to allow them to carry out their own evidencebased decision making in the future. The degree of discrepancy in the Catalyst case sits in between the AtollGame and the Hawkesbury projects. At the time the evaluation was carried out approximately 18 months had passed since many Catalyst participants had been involved in the project. Unlike the AtollGame project whereby the majority of participants were involved in a 2-day workshop only, the 
Catalyst process involved stakeholders over a two year period. It is important to note that the project team carried out their own on-going evaluation throughout the process which they also used to improve the project's design. Internal on-going evaluations would have increased the degree to which the project team and participants' perception of the process overlap when carrying out an external evaluation using the Protocol of Canberra.

\section{CONCLUSION}

Participatory modeling requires a dedicated framework for the purposes of evaluation. We have argued that the Protocol of Canberra is suitable for a broad range of evaluation tasks which combine participation and modeling approaches, and can be applied as either an on-going or ex-post evaluation. Through its application to date, the Protocol of Canberra framework appears more suited to ongoing evaluations as rich evaluation data can be collected by directly observing participatory (modeling) procedures and informally interacting with participants throughout the process. The project team are better able to articulate the theoretical assumptions of their proposed methodology - including how they perceive it to play out in practice - as it progresses rather then reflecting back to the (sometimes distant) past. Participants are likewise able to articulate their experiences of the process more easily in an on-going form of evaluation. Another positive aspect is that on-going evaluation data can be fed back into a project process to make improvements.

A key strength of the Protocol of Canberra evaluation framework is the ability to highlight striking differences in perceptions of project teams and community participants, as demonstrated by the trial applications presented in this paper. The cases presented here suggest a correlation between the extent of the difference and 
the length of time between a project's implementation and evaluation. This flags an important issue to follow up when comparing across other participatory modeling projects. The cases discussed here show that an on-going form of evaluation increases the degree of overlap in the project teams' and participants perspectives of the process. The subsequent stages of a project can be designed around this shared understanding of the project's achievements (positive and negative). The Protocol of Canberra can be used to guide this design process as it challenges a project team to articulate 'why' and 'how' they intend to use certain techniques and procedures within a certain context. Comparing the success of projects involving an on-going evaluation with those involving an ex-post evaluation adds an additional point of comparison which will potentially assist in further improving the participatory modeling approach overall.

\section{ACKNOWLEDGEMENTS}

This research was supported by CIRAD (France) and CSIRO-CSS (Australia). The evaluation framework and case studies are part of an international project called ADD-ComMod, led by INRA (France) and funded by the Agence Nationale de Recherche (France). Thanks to Russell Goddard (CSIRO Sustainable Ecosystems (CSE)) for facilitating the Catalyst study evaluation, Pieter Bots (Delft University of Technology) for assistance with Figure 1, and Rachel Williams and Kostas Alexandridis (CSE) for helpful comments on the draft manuscript. Thank you especially to the participants and project teams of the case studies, who gave their time to complete the evaluation procedures. 


\section{REFERENCES}

Agence Nationale de la Recherche (ANR) (2005) Programme Federateur "Agriculture et Developpement Durable":13-14.

<http://www.agence-nationale-recherche.fr/documents/aap/resultatADD05.pdf>

Alexandridis, K. and Measham, T.G. (2007). Modeling Grazing Viability in Outback Australia using Bayesian Livelihood Networks. CSIRO Technical Report, July 2007. Canberra, ACT: CSIRO Sustainable Ecosystems: 65.

Arnstein, S.R. (1969) A Ladder of Citizen Participation, Journal of the American Institute of Planners 35 (4): 216-224.

Barreteau, O., Le Page, C. and Perez , P. (2007) Contribution of Simulation and Gaming to Natural Resource Management Issues : an introduction. Simulation and Gaming 38 (2):185.

Blackstock, K.L., Kelly, G.J. and Horsey, B.L. (2007) Developing and Applying a Framework to Evaluate Participatory Research for Sustainability. Ecological Economics 60 (4): 726-742.

Bousquet F., Barreteau O., D'Aquino P., Etienne M., Boissau S., Aubert S., Le page C., Babin D. and Castella J.-C (2002) Multi-Agent Systems and Role Games: Collective Learning processes for Ecosystem Management. In: Complexity and Ecosystem Management: the theory and practice of multi-agent systems. M.A. Janssen (ed.). Edward Elgar Publishers: 248-285.

Brown, V. and Pitcher, J. (2005). Linking community and government: islands and beaches. In Social Learning in Environmental Management: Towards a sustainable future. M. Keen, V. Brown and R. Dyball (eds.). London: James and James/Earthscan, 45-123.

Cash, D.W., Clark, W.C., Alcock, F., Dickson, N.M., Eckley, N., Guston D.H, Jager, J. and Mitchell, R.B. (2003) Knowledge Systems for Sustainable Development. PNAS 100 (14): 8086-8091.

ComMod (2004) ComMod: a companion modeling approach, Charter Version 1.1, Online [URL]. <http://cormas.cirad.fr/ComMod/en/charter/content.htm>

Costanza, R. and Ruth, M. (1998) Using Dynamic Modeling to Scope Environmental Problems and Build Consensus. Environmental Management 22: 183-195.

Curnan, S., LaCava, L., Sharpstee, D., Lelle, M. and Reece, M. (1998) W.K Kellogg Foundation Evaluation Handbook.

<http://www.wkkf.org/pubs/Tools/Evaluation/Pub770.pdf>

Funtowicz, S.O. and Ravetz, J.R. (1991) A New Scientific Methodology for Global Environmental Issues. In Ecological Economics : the science and management of sustainability. R. Costanza. New York: Columbia University Press, 52-137.

Daniell, K.A. and Ferrand, N. (2006) Participatory Modelling for Water Resources Management and Planning, D3.8.2. Aquastress IP, FP6, Europe.

Daniell, K.A. (2007) Summary Report: Stakeholder Workshops 2 and 3 for the Lower Hawkesbury Estuary Management Plan. LHEMP project report prepared for the Hornsby Shire Council and BMT WBM, Fenner School, Australian National University, 76. 
Dray, A., Perez, P., Jones, N., Le Page, C., D’Aquino, P., White, I. and Auatabu, T. (2006) The AtollGame Experience: from knowledge engineering to a computer-assisted role playing game. Journal of Artificial Societies and Social Simulation 9 (1). <http://jasss.soc.surrey.ac.uk/9/1/6.html>

Dray, A., Perez, P., Le Page, C., D'Aquino, P. and White, I. (2007) Who wants to terminate the game? The role of vested interests and metaplayers in the ATOLLGAME experience. Simulation and Gaming: May 2007.

Gorddard, R. (2005) Central Coast Regional Futures Planning Project: A Research Partnership to help the Communities and Governments of the Central Coast (NSW) develop a capacity for evidence-based Strategic Planning. Final Report, CSIRO Sustainable Ecosystems, Canberra.

HarmoniCOP (2005) Learning Together to Manage Together: improving participation in water management. HarmoniCOP, Europe.

<http://www.harmonicop.info/HarmoniCOPHandbook.pdf>

Hisschemoller, R., Tol, R.S.J. and Vellinga, P. (2001) The Relevance of Participatory Approaches in Integrated Environmental Assessment. Integrated Assessment 2: 57-72.

Kazi, M. (2003) Realist Evaluation for Practice. British Journal of Social Work 33 (6): 803-818.

Kelly, G. and Walker, P. (2004) Community-Level Systems Thinking. $2^{\text {nd }}$ International Conference of the System Dynamics Society, Oxford.

Lynam, T., de Jong, W., Sheil, W., Kusumanto, T. and Evans, K. (2007) A Review of Tools for Incorporating Community Knowledge, Preferences and Values into Decision Making in Natural Resource Management. Ecology and Society 12 (1). <http://www.ecologyandsociety.org/vol12/iss1/art5/>

Maurel, P., Flavie, C., Ferrand, N., Marc, C. and Valkering, P. (2004) Some Methodological Concepts to Analyse the Role of IC-tools in Social Learning Processes. HarmoniCOP Work Package 3. International Environmental Modeling and Software Society (iEMSs). <http://citeseer.ist.psu.edu/maurel04some.html>

McAllister, R.R.J., Gordon, I.J., Janssen, M.A. and Abel, N. (2006). Pastoralists' Responses To Variation Of Rangeland Resources In Time And Space. Ecological Applications 16 (2): 572-83.

Mead, G.H. (1993) Mind, Self and Society. Chicago: University of Chicago Press.

Mostert, E. (2003) The European Water Framework Directive and water management research. Physics and Chemistry of the Earth 28 (12-13): 523527.

Mostert, E., Pahl-Wostl, C., Rees, Y., Searle. B., Tabara, D. and Tippett, J. (2007) Social Learning in European River-Basin Management: barriers and fostering mechanisms from 10 river basin. Ecology and Society 12 (1): 19.

Patton, M.Q. (1990) Qualitative evaluation and research methods (2 ${ }^{\text {nd }}$ edition). California, Newbury Park: Sage Publications. 
Phillips, H.P. (1960) Problems of translation and meaning in field work. In Human Organisation Research: Field Relations and Techniques. R.N. Adams and J.J. Preiss (eds.). Homewood, ILL: Dorsey Press Inc.

Perez, P. and Batten, D.F. (eds.) (2003) Complex Science for a Complex World: exploring human ecosystems with agents. Canberra, Australia: ANU E-Press.

Reed, M., Fraser, D.G., Morse, S. and Dougill, A.J. (2005) Integrating Methods for Developing Sustainability Indicators to Facilitate Learning and Action. Ecology and Society 10 (1). <http://www.ecologyandsociety.org/vol10/iss1/resp3>

Siebenhuner, V. and Barth, V. (2005) The Role of Computer Modeling in Participatory Integrated Assessments. Environmental Impact Assessment Review 25: 367-389.

Webler, T. (1999) The Craft and Theory of Public Participation: a dialectical process: Journal of Risk Research 2 (1): 55-71.

Weiss, C,H., (1995) Nothing as Practical as Good Theory: Exploring Theory-Based Evaluation for Comprehensive Community Initiatives for Children and Families. In New Approaches to Evaluating Community Initiatives: Concepts, Methods and Contexts. James P. Connell, Anne C. Kubisch, Lisbeth B. Schorr and Carol H. Weiss (eds.). Washington D.C.: The Aspen Institute.

World Bank Operations Evaluation Department (2004) Monitoring and Evaluation: some tools, methods and approaches. Washington D.C: The World Bank. <http://www.agence-nationale-recherche.fr/documents/aap/resultatADD05.pdf> 
Figure 1. Graphical schematic of the Protocol of Canberra Evaluation Framework (adapted from P. Bots, personal communication)

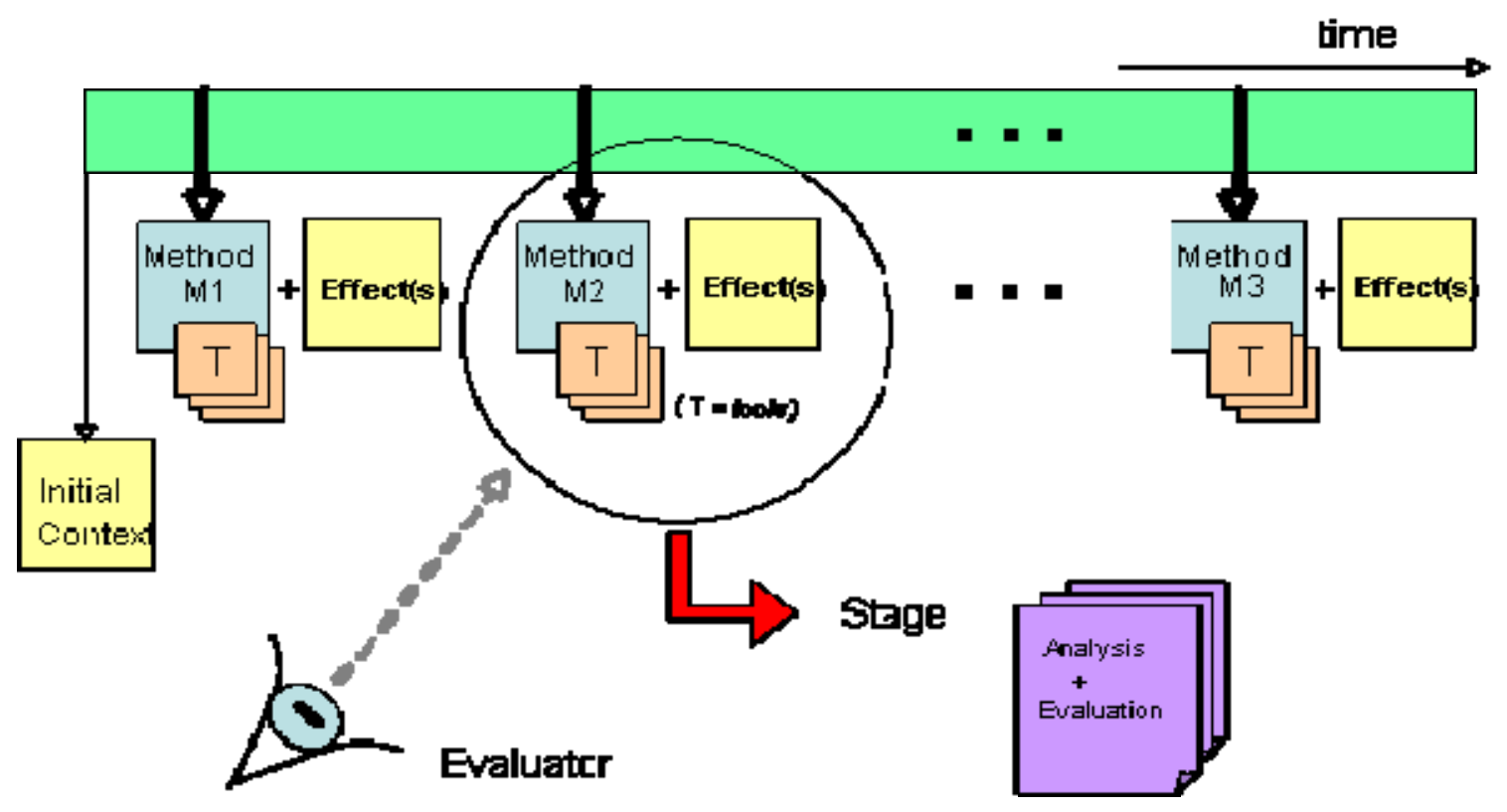


Figure 2. Graphical outline of the Protocol of Canberra

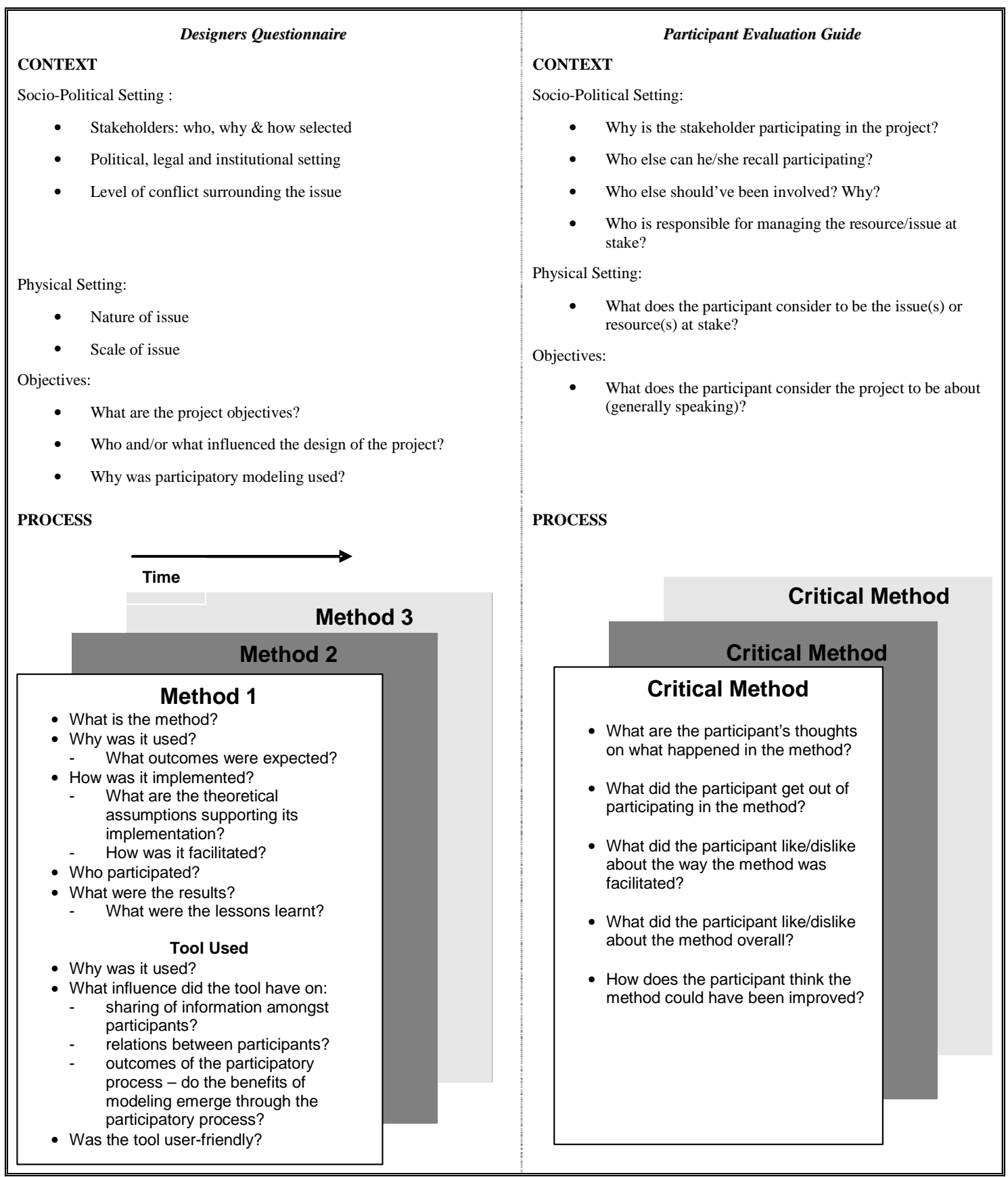


Table 1. Benefits of model use (Siebenhuner and Barth 2005)

\section{Benefits of Model Use}

- Provides a shared understanding of environmental and social issues and their impacts.

- Seeks to analyse the causes of problems or issues.

- Explores and assesses management options and strategies.

- Supports the structuring and formulation of goals and objectives.

Table 2. Purposes of participatory processes (Siebenhuner and Barth 2005, Blackstock et al., 2007)

\section{Purposes of Participatory Processes}

- Normative Function: increases the legitimacy of the process of knowledge generation through the involvement of a range of stakeholder groups. Enhancing social and individual learning benefits both individual citizens and society.

- Substantive Function: allows for greater integration of more sources of knowledge and greater capacity for problem solving. An increased understanding of issues will assist in selecting appropriate solutions.

- Instrumental Function: focusing on building collaborative relationships assists with implementation and reducing conflict. People's commitment to the outcomes of the process is increased. 
Table 3. Data collection methods to inform the Protocol of Canberra

\begin{tabular}{|c|c|c|}
\hline $\begin{array}{l}\text { Protocol of Canberra } \\
\text { Component }\end{array}$ & Espoused Theory & Theory in Use \\
\hline $\begin{array}{l}\text { Designers Questionnaire } \\
\text { (DQ) - captures the } \\
\text { project team's } \\
\text { experiences of the } \\
\text { project }\end{array}$ & $\begin{array}{l}\text { - Interview with project } \\
\text { team } \\
\text { - Project documents }\end{array}$ & $\begin{array}{ll}\text { - } & \text { Interview(s) with } \\
\text { project team } \\
\text { - } & \text { Project documents } \\
\text { - } & \text { Observations (for on- } \\
\text { going projects) } \\
\text { - } & \text { Prior project } \\
\text { evaluations }\end{array}$ \\
\hline $\begin{array}{l}\text { Participants Evaluation } \\
\text { Guide (PEG) - captures } \\
\text { the participants' } \\
\text { experiences of the } \\
\text { project }\end{array}$ & & $\begin{array}{ll}\text { - } & \text { Interview with } \\
\text { participants } \\
\text { - } \\
\text { - } \text { Questionnaire } \\
\text { with participants (for } \\
\text { on-going projects) } \\
\text { - } \begin{array}{l}\text { Prior project } \\
\text { evaluations }\end{array}\end{array}$ \\
\hline
\end{tabular}

Table 4. Three contrasted case-studies evaluated using the Protocol of Canberra.

\begin{tabular}{llll}
\hline \multicolumn{1}{c}{ Case study } & \multicolumn{1}{c}{ Topic } & Methods and Tools & \multicolumn{1}{c}{$\begin{array}{c}\text { Evaluation } \\
\text { stage }\end{array}$} \\
\hline $\begin{array}{l}\text { AtollGame } \\
\text { (Dray et al, }\end{array}$ & $\begin{array}{l}\text { Groundwater co- } \\
\text { management }\end{array}$ & $\begin{array}{l}\text { Companion modeling: } \\
\text { Carawa, Republic of }\end{array}$ & ex-post \\
& Kiribati & & \\
Hawkesbury & Estuary management plan & Participatory modeling: & on-going \\
$\begin{array}{l}\text { (Daniell, 2007) } \\
\text { NSW, Australia }\end{array}$ & Risk assessment matrix & \\
$\begin{array}{l}\text { Catalyst } \\
\text { (Goddard, }\end{array}$ & $\begin{array}{l}\text { Regional planning and } \\
\text { development }\end{array}$ & Participatory modeling: & ex-post \\
& NSW, Australia & Futures Simulator & \\
& & & \\
\hline
\end{tabular}


Table 5. Overview of the AtollGame evaluation

\begin{tabular}{|c|c|c|c|}
\hline \multicolumn{2}{|c|}{ Evaluation Data Collection } & \multirow[b]{2}{*}{ Identified methods } & \multirow[b]{2}{*}{ Asserted effects } \\
\hline $\begin{array}{c}\text { Designer's } \\
\text { Questionnaire }\end{array}$ & $\begin{array}{l}\text { Participant's } \\
\text { Eval. Guide }\end{array}$ & & \\
\hline $\begin{array}{l}\text { - Project } \\
\text { documents } \\
\text { - Interview with } \\
\text { project team (2 } \\
\text { members); 5hrs } \\
\text { duration }\end{array}$ & $\begin{array}{l}\text { - Semi- } \\
\text { structured } \\
\text { interviews with } \\
13 \text { participants; } \\
\text { average } \\
\text { 30mins } \\
\text { duration }\end{array}$ & $\begin{array}{l}\text { - Global Targeted } \\
\text { Assessment } \\
\text { - Computer-Assisted } \\
\text { Role Playing Game } \\
\text { (RPG) }\end{array}$ & $\begin{array}{l}\text { Understanding collective } \\
\text { mental models } \\
\text { Collective set of solutions, } \\
\text { communication }\end{array}$ \\
\hline
\end{tabular}


Table 6. AtollGame evaluation data

\begin{tabular}{|c|c|}
\hline DESIGNER'S VIEWS & PARTICIPANTS' VIEWS \\
\hline Creating a Space of Exchange & \\
\hline $\begin{array}{l}\text { Points of Alignment: } \\
\text { - Playful exercise which succeeded in } \\
\text { creating non-threatening environment. } \\
\text { Participants with differing points of view on } \\
\text { groundwater issue worked together in non- } \\
\text { confrontational atmosphere. } \\
\text { - The game put a spotlight on issues } \\
\text { believed to be driving whole system: land } \\
\text { tenure, land market and water } \\
\text { management. Tensions surrounding these } \\
\text { issues surfaced, igniting lively discussions. }\end{array}$ & $\begin{array}{l}\text { - All interviewees claim that they were } \\
\text { effectively able to express their views on } \\
\text { the issue. } \\
\text { - One interviewee comments that land } \\
\text { issues are rarely discussed outside the } \\
\text { family. He adds: "I was kind of relieved in a } \\
\text { sense that other people thought the same } \\
\text { way as myself and I was able to learn from } \\
\text { those people as well, the whole sharing of } \\
\text { ideas". }\end{array}$ \\
\hline $\begin{array}{l}\text { Points of Discrepancy: } \\
\text { - Ensure players speak English. RPG was } \\
\text { run in I-Kiribati language meaning a lot of } \\
\text { information collected will never be } \\
\text { analysed. }\end{array}$ & $\begin{array}{l}\text { - In contrast to designers, one interviewee } \\
\text { commented he liked that the game was } \\
\text { conducted in I-Kiribati: "The good thing } \\
\text { about the game is that it is conducted in } \\
\text { our own language so communication is } \\
\text { really effective, getting across to each } \\
\text { other, to understand each other". }\end{array}$ \\
\hline $\begin{array}{l}\text { Points of Interest: } \\
\text { - Some participants proved open to } \\
\text { negotiate, others maintained their hard- } \\
\text { lined position. The latter were not prepared } \\
\text { to compromise and locked final } \\
\text { discussions. } \\
\text { - The RPG could be simpler - some } \\
\text { participants appeared lost at times. }\end{array}$ & $\begin{array}{l}\text { - The game allowed players to express } \\
\text { negative views on water management } \\
\text { issue. An interviewee states negotiation } \\
\text { processes in reality are influenced by } \\
\text { culture and conducted in a polite manner. } \\
\text { - RPG created a sense of empathy for a few } \\
\text { interviewees. } \\
\text { - In terms of the 'Space of Exchange' } \\
\text { evolving, some landowners felt they're in a } \\
\text { better position to negotiate with the } \\
\text { government in the future due to their } \\
\text { increased understanding of water issues. }\end{array}$ \\
\hline
\end{tabular}




\begin{tabular}{|c|c|}
\hline \multicolumn{2}{|l|}{ Shared Knowledge } \\
\hline $\begin{array}{l}\text { Points of Interest: } \\
\text { - In the final stages, a collective debate on } \\
\text { water management prompted the project } \\
\text { team to formally engage participants in } \\
\text { building flowchart of potential financial, } \\
\text { technical and socials solutions. Collective } \\
\text { analysis of the flowchart concluded that } \\
\text { situation as it stood was unsustainable } \\
\text { from both a financial and social viewpoint. } \\
\text { Discussions surrounding the flowchart } \\
\text { were hindered by those taking a hard-lined } \\
\text { stance on the issues as well as the limited } \\
\text { amount of time available. }\end{array}$ & $\begin{array}{l}\text { - Interviewees did not comment on this } \\
\text { issue. }\end{array}$ \\
\hline Promoting Collective Practices & \\
\hline $\begin{array}{l}\text { Points of Interest: } \\
\text { - RPG failed to lead to collective practices } \\
\text { for two identified reasons: (i) domination of } \\
\text { hard-lined players and (ii) lack of } \\
\text { involvement of meta-players. The former } \\
\text { locked final discussions preventing the } \\
\text { workshop from progressing towards } \\
\text { collective agreement on practices to } \\
\text { pursue. Meta-players represent the } \\
\text { overarching funding body and have a } \\
\text { strong influence on the direction of the } \\
\text { overall project. The funding body decided } \\
\text { to pursue their own solutions, ignoring } \\
\text { outcomes of the RPG workshop which } \\
\text { provided a tentative road map for future } \\
\text { negotiations. }\end{array}$ & $\begin{array}{l}\text { - For the landowners, most valuable aspect } \\
\text { of participating in the RPG was the } \\
\text { individual knowledge gained about how } \\
\text { their own family, and in some cases } \\
\text { village, could better manage their } \\
\text { groundwater source. This was about } \\
\text { changing their behavior to ensure their } \\
\text { water be kept clean. Many landowners saw } \\
\text { this as the objective of the project } \\
\text { - Majority of landowners stated they had } \\
\text { changed their practices in some way, } \\
\text { reducing their impact on the quality of } \\
\text { groundwater supply. }\end{array}$ \\
\hline
\end{tabular}


Table 7. Overview of the Catalyst evaluation

\begin{tabular}{|c|c|c|c|}
\hline \multicolumn{2}{|c|}{ Evaluation Data Collection } & \multirow[b]{2}{*}{ Identified methods } & \multirow[b]{2}{*}{ Asserted effects } \\
\hline $\begin{array}{c}\text { Designer's } \\
\text { Questionnaire }\end{array}$ & $\begin{array}{l}\text { Participant's } \\
\text { Eval. Guide }\end{array}$ & & \\
\hline $\begin{array}{l}\text { - Project } \\
\text { documents } \\
\text { - Interview } \\
\text { with project } \\
\text { team (2 } \\
\text { members); } \\
\text { 8hrs } \\
\text { duration. }\end{array}$ & $\begin{array}{l}\text { - Semi- } \\
\text { structured } \\
\text { interviews with } \\
8 \text { participants; } \\
\text { 1hr duration } \\
\text { (average). }\end{array}$ & $\begin{array}{l}\text { - General Orientation Visits } \\
\text { and Regional Overview } \\
\text { - Assess Commitment and } \\
\text { Partnership Agreement } \\
\text { - Oral History Interviews } \\
\text { - Mapping Regional } \\
\text { Research and Develop } \\
\text { Regional Baseline } \\
\text { - Systems Workshops: } \\
\text { Understand Regions as } \\
\text { Systems (using systems } \\
\text { diagrams) } \\
\text { - Scenario Workshops: } \\
\text { Charting Investment } \\
\text { Strategies } \\
\text { Simulator: Charting and } \\
\text { Building Resilient Futures } \\
\end{array}$ & $\begin{array}{l}\text { Explore possible futures } \\
\text { and the pathways that lead } \\
\text { there. } \\
\\
\text { Involve local stakeholders } \\
\text { in building a computer } \\
\text { model that is like a low-cost } \\
\text { learning laboratory where } \\
\text { decision-makers can } \\
\text { explore development } \\
\text { strategies. }\end{array}$ \\
\hline & & - Forum and Handover & $\begin{array}{l}>\text { Hand over the Futures } \\
\text { Simulator }\end{array}$ \\
\hline
\end{tabular}

Table 8. Catalyst evaluation data 


\begin{tabular}{|c|c|}
\hline DESIGNER'S VIEWS & PARTICIPANTS' VIEWS \\
\hline Creating a Space of Exchange & \\
\hline $\begin{array}{l}\text { Points of Alignment: } \\
\text { - Systems diagrams proved effective way to } \\
\text { identify key drivers of system in that a story } \\
\text { is built up sequentially by participants } \\
\text { through team learning. Workshops gave } \\
\text { everyone an opportunity to stake claims } \\
\text { and be heard in non-confrontational } \\
\text { atmosphere. Everyone treated equally and } \\
\text { all views acknowledged. } \\
\text { - More facilitation training needed. } \\
\text { - Scenario workshops were less successful. } \\
\text { These workshops were intended to identify } \\
\text { set of plausible strategies to form the basis } \\
\text { of the Futures Simulator. Some } \\
\text { participants were unaware of the intent of } \\
\text { exploring the scenarios and were confused } \\
\text { over what the output of the workshop } \\
\text { would be used for. } \\
\text { - Acknowledged that the length of time of } \\
\text { the project was problematic for } \\
\text { participants. }\end{array}$ & $\begin{array}{l}\text { - All participants (except one) agreed } \\
\text { systems diagramming workshops were } \\
\text { most successful aspect of process. Non- } \\
\text { confrontational atmosphere created } \\
\text { despite highly politicised nature of planning } \\
\text { in region. } \\
\text { - Majority of interviewees said facilitation } \\
\text { could have been improved. } \\
\text { - Majority of participants confirm views of } \\
\text { project team regarding scenario } \\
\text { workshops. These workshops failed to } \\
\text { create space of exchange where people } \\
\text { felt comfortable sharing their opinions. } \\
\text { - Timing of project proved to be hindrance in } \\
\text { ensuring space of exchange evolved. Long } \\
\text { time-gaps between the workshops reduced } \\
\text { some participants' motivation to remain } \\
\text { involved in project, while others took on } \\
\text { new employment within 3-year life of } \\
\text { project leaving a replacement to fulfill their } \\
\text { role in Catalyst. }\end{array}$ \\
\hline $\begin{array}{l}\text { Points of Interest: } \\
\text { - Stakeholders placed too much emphasis } \\
\text { on the model - the Futures Simulator - } \\
\text { and not enough on the capacity building } \\
\text { 'process' in which it was embedded. }\end{array}$ & $\begin{array}{l}\text { - Interviewees did not comment on this } \\
\text { issue. }\end{array}$ \\
\hline
\end{tabular}




\section{Shared Knowledge}

\section{Points of Alignment:}

- Through the systems workshops "[Participants] 'see' how their mental model 'fits' with the larger view, and are better able to acknowledge and value others' views different from their own" (Kelly and Walker 2004: 9). Key issues identified in these workshops are used to start building scenarios.
- Majority of interviewees stated they valued the ability to view regional planning from systems thinking perspective. One participant stated: "People were willing to listen to everybody else, 'but what about this issue or what about that issue, can we put that in?' It wasn't a case of, 'Oh, I don't think so'. It was a case of where will it fit and then once the subject matter was up there, then pretty much everyone in the group were able to add what effects what".

\section{Points of Interest:}

- Scenario workshops were intended as 'community visioning' exercise whereby participants collectively imagine their most desired future. In practice these workshops were less successful in building collective knowledge as scenarios covered were too broad and too numerous for participants to explore. Participants were confused on what to do.

- Project focused on developing capacity of region to build on their collective knowledge in the future using systems thinking tools and practices. At the conclusion of the project, the region failed to secure sense of ownership over the RDF cycle and Futures Simulator.
- Integration of knowledge - arising from the series of workshops and other data collection activities - into the model was questionable to a few participants, particularly those less technically minded and/or did not have great deal of time to dedicate to the model building process.

- Majority of participants would like to see the RDF cycle and Futures Simulator (with a few modifications) adopted by region and used as tool to assist decision making processes in the future.

\section{Promoting Collective Practices}

\section{Points of Alignment:}

- At the conclusion of the project it was recognised that the model could not be used by the region in the state it was handed over. To modify the model requires a high degree of skill and technical ability; currently CSIRO alone have that capacity.
- Many interviewees agree that modifications are necessary to make the tools accessible and useable. 
Table 9. Overview of the Hawkesbury case-study evaluation

\begin{tabular}{|c|c|c|c|}
\hline \multicolumn{2}{|c|}{ Evaluation Data Collection } & \multirow[b]{2}{*}{ Identified Methods } & \multirow[b]{2}{*}{ Asserted Effects } \\
\hline $\begin{array}{c}\text { Designer's } \\
\text { Questionnaire } \\
\text { (DQ) }\end{array}$ & $\begin{array}{l}\text { Participant's } \\
\text { Eval. Guide } \\
\text { (PEG) }\end{array}$ & & \\
\hline $\begin{array}{l}\text { - Project } \\
\text { documents } \\
\text { - Interview with } \\
\text { project team } \\
\text { (3 members); } \\
\text { intermittently } \\
\text { over the } \\
\text { length of the } \\
\text { project (5 } \\
\text { months) } \\
\\
\text { - Evaluator's } \\
\text { observations } \\
\text { and informal } \\
\text { interactions } \\
\text { with } \\
\text { participants }\end{array}$ & $\begin{array}{l}\text { - Questionnaires } \\
\text { consisting of } \\
\text { closed and } \\
\text { open-ended } \\
\text { questions } \\
\text { - Total of } 40 \\
\text { filled in over } \\
\text { series of } 3 \\
\text { workshops; } \\
\text { average return } \\
\text { rate of } 60 \% ; \\
\text { average of } 15 \\
\text { minutes to } \\
\text { complete. }\end{array}$ & $\begin{array}{l}\text { - Workshop No. 2: } \\
\text { Risk Analysis } \\
\text { - Workshop No. 3: } \\
\text { Strategy Formulation }\end{array}$ & $\begin{array}{l}\quad \text { Identify } \\
\text { stakeholders' values } \\
\text { and issues related to } \\
\text { the estuary; and; } \\
\text { Identify overall goals } \\
\text { and a vision for the } \\
\text { estuary. }\end{array}$ \\
\hline
\end{tabular}


Table 10. Hawkesbury evaluation data

\begin{tabular}{|c|c|}
\hline DESIGNER'S VIEWS & PARTICIPANTS' VIEWS \\
\hline Creating a Space of Exchange & \\
\hline $\begin{array}{l}\text { Points of Alignment: } \\
\text { - Workshop succeeded in creating a space } \\
\text { of exchange where people felt comfortable } \\
\text { putting forth their point of view in non- } \\
\text { confronting manner. } \\
\text { - Participants appeared more open and } \\
\text { vocal than in previous workshop. Agency } \\
\text { representatives felt less threatened without } \\
\text { community present (as in previous } \\
\text { workshop). } \\
\text { - Space of exchange was inhibited in that at } \\
\text { least one participant felt it unethical to } \\
\text { endorse some of the data presented (as } \\
\text { called for by the project team) without input } \\
\text { from the community also (this was } \\
\text { addressed in the following Workshop). } \\
\text { - Time constraints meant participants } \\
\text { worked in pairs rather then small groups } \\
\text { meaning they exchanged ideas with fewer } \\
\text { people then anticipated. }\end{array}$ & $\begin{array}{l}\text { - Majority of interviewees responded } \\
\text { positively to space of exchange created } \\
\text { through the workshop. } \\
\text { - One interviewee specified the value of } \\
\text { holding 'agency' discussions. Two other } \\
\text { interviewees described the interactions as } \\
\text { 'honest' and 'open'. } \\
\text { - Many participants supported the DQ in } \\
\text { stating that there was insufficient time to } \\
\text { effectively assess all risks presented in } \\
\text { workshop. }\end{array}$ \\
\hline Shared Knowledge & \\
\hline $\begin{array}{l}\text { Points of Alignment: } \\
\text { - While this exercise served as a knowledge } \\
\text { integration exercise (using the risk matrix } \\
\text { and mathematical model) rather then a } \\
\text { knowledge building exercise, some } \\
\text { participants assessed risks they claimed to } \\
\text { not know much about. This was however } \\
\text { captured by including a scalar category for } \\
\text { "uncertainty". } \\
\text { - Working in pairs rather small groups due to } \\
\text { time constraints meant that the wealth of } \\
\text { specialised knowledge in the room was } \\
\text { dispersed and not necessarily channeled } \\
\text { in the most appropriate directions, i.e. } \\
\text { towards risks suited to a participant's area } \\
\text { of expertise. A literature review was carried } \\
\text { out by the project team, however, to } \\
\text { address this. }\end{array}$ & $\begin{array}{l}\text { - Two interviewees support the DQ stating } \\
\text { that working in pairs was less desirable } \\
\text { then in groups. Responding to the question } \\
\text { 'Were objectives satisfactorily achieved'? A } \\
\text { participant replied: "Not clear yet - there } \\
\text { were challenges especially related to } \\
\text { pockets of information spread between } \\
\text { attendees". }\end{array}$ \\
\hline Promoting Collective Practices & \\
\hline
\end{tabular}




\section{Points of Interest:}

- This Workshop focused on identifying, prioritising and classifying risks that need to be managed. The $3^{\text {rd }}$ Workshop was primarily concerned with formulating strategies to treat the risks. Hence, no collective practices emerged from this stage of the project (as intended by the

- Reflecting on the most important thing learnt in the workshop, one participant acknowledged the collective effort of the participating group and the value it holds in moving forward: "...there are some good people working to protect the catchment. project team). 